\title{
Analyzing Somatosensory Axon Projections with the Sensory Neuron-Specific Advillin Gene
}

\author{
Hiroshi Hasegawa, Sara Abbott, Bao-Xia Han, Yi Qi, and Fan Wang \\ Department of Cell Biology, Duke University Medical Center, Durham, North Carolina 27710
}

\begin{abstract}
Peripheral sensory neurons detect diverse physical stimuli and transmit the information into the CNS. At present, the genetic tools for specifically studying the development, plasticity, and regeneration of the sensory axon projections are limited. We found that the gene encoding Advillin, an actin binding protein that belongs to the gelsolin superfamily, is expressed almost exclusively in peripheral sensory neurons. We next generated a line of knock-in mice in which the start codon of the Advillin is replaced by the gene encoding human placenta alkaline phosphatase (Avil-hPLAP mice). In heterozygous Avil-hPLAP mice, sensory axons, the exquisite sensory endings, as well as the fine central axonal collaterals can be clearly visualized with a simple alkaline phosphatase staining. Using this mouse line, we found that the development of peripheral target innervation and sensory ending formation is an ordered process with specific timing depending on sensory modalities. This is also true for the in-growth of central axonal collaterals into the brainstem and the spinal cord. Our results demonstrate that Avil-hPLAP mouse is a valuable tool for specifically studying peripheral sensory neurons. Functionally, we found that the regenerative axon growth of Advillin-null sensory neurons is significantly shortened and that deletion of Advillin reduces the plasticity of whisker-related barrelettes patterns in the hindbrain.
\end{abstract}

Key words: sensory ganglia; genetic labeling; sensory ending; central collateral projection; hPLAP; Advillin

\section{Introduction}

The peripheral sensory neurons detect various stimuli that the physical world impinges on the body and transmit that information to the brain. The somatic sensory neurons, in particular, detect painful, thermal, mechanical, or proprioceptive stimuli. These neurons have their cell bodies located in a series of ganglia: the dorsal root ganglia (DRG) for trunk sensory neurons, the trigeminal ganglia (TG), or the trigeminal mesencephalic nuclei (Me5) for face somatosensory neurons. All peripheral sensory neurons are derived either from neural crest cells (precursors for majority of the neurons) or from cells in the neurogenic placodes (origin for many of the cranioganglia neurons) (for review, see Streit, 2004; Schlosser, 2006).

Somatosensory neurons possess two major axonal branches originated from one unipolar axon growing out of the cell body: a peripheral branch that innervates peripheral targets such as hair, skin, internal organs, and muscles and a central axon that projects collaterals into the spinal cord or the brainstem and forms topographic representations of the body (Willis and Coggeshall, 1988; Rowe and Iwamura, 2001). However, the molecular mechanisms that guide these precise peripheral and central

Received May 11, 2007; accepted Nov. 16, 2007.

This work was supported by National Institute of Dental and Craniofacial Research Grant 5R01DE16550, the Alfred A. Sloan Foundation, the Klingenstein Fund, the Whitehall Foundation (F.W.), and by fellowships from Uehara Memorial Foundation and Japan Society for the Promotion of Science (H.H.). We thank Dr. David Anderson for providing CPLAP-ACN cassette. We also thank members of the Wang laboratory for technical help as well as useful discussions and comments.

Correspondence should be addressed to Fan Wang, Department of Cell Biology, Duke University Medical Center, Box 3709, Durham, NC27710. E-mail: f.wang@cellbio.duke.edu.

D0I:10.1523/JNEUROSCI.4908-07.2007

Copyright $\odot 2007$ Society for Neuroscience $\quad$ 0270-6474/07/2714404-11\$15.00/0 projections are still primarily unknown at present. To study this, we developed a genetic tool that would allow us to easily and specifically visualize both the sensory endings and the central collateral projections of sensory neurons. Traditionally, detection of these sensory fibers has depended on staining with various antibodies or tracing with dyes. These methods can be technically challenging, expensive, or unsuitable for developmental studies and large-scale analyses. To circumvent these problems, we generated a knock-in mouse line based on the Advillin gene locus in which peripheral sensory neurons and all of their processes can be specifically visualized by a simple alkaline phosphatase staining.

Advillin is a member of the gelsolin superfamily of actin binding proteins (Marks et al., 1998; Ravenall et al., 2002). We performed a detailed in situ hybridization analysis and found that Advillin mRNA is almost exclusively expressed by peripheral sensory neurons throughout the development and into adulthood. We generated Avil-hPLAP mice in which the human placental alkaline phosphatase ( $h P L A P$ ) gene replaced the start codon of Advillin gene. hPLAP protein is heat-insensitive and membranebound and is transported to the surface of axons (Leighton et al., 2001; Shah et al., 2004; Zylka et al., 2005). Using Avil-hPLAP mice, we analyzed the development of both peripheral sensory endings and the central axonal connectivity for trigeminal and DRG neurons over embryonic stages. We found that different peripheral targets are not simultaneously innervated, and that sensory neurons engage their targets early during development but do not form specialized endings until much later. There is also an ordered in-growth of the central axonal collaterals. Analyses of Avil-hPLAP homozygous mice showed that in vitro regenerative sensory axon outgrowth is impaired. Also, the mutant mice showed the reduced whisker lesion-induced plasticity in the 
barrelettes patterns. Together, these data support a role of Advillin protein in axonal remodeling and regrowth.

\section{Materials and Methods}

Generation of Avil-hPLAP mutant mice. The Advillin genomic clone was subcloned using PCR from genomic DNA of embryonic stem (ES) cells followed by sequencing. We constructed the targeting vector by inserting the hPLAP-ACN cassette, which was kindly provided by Dr. David Anderson (California Institute of Technology, Pasadena, CA) (Zylka et al., 2005), into the translation start ATG of the Advillin gene by a PCRbased method. Targeted ES cells were generated and confirmed by Southern blotting.

To detect the Avil-hPLAP mutant allele by PCR, PCR primers were designed as follows: Avil/003, 5'-CCCTGTTCACTGTGAGTAGG-3'; Avil/002, 5'-AGTATCTGGTAGGTGCTTCCAG-3'; hPLAP/03, 5' ATCGCCCAGGAAGATGATGAG-3'. The wild-type allele produces a $\sim 500$ bp fragment with Avil/003 and Avil/002 primers, whereas the mutant allele is detected by a $\sim 350 \mathrm{bp}$ fragment with Avil/003 and $h P L A P / 03$ primers. All experiments were conducted according to protocols approved by The Duke University Institutional Animal Care and Use Committee.

In situ hybridization and costaining with anti-neuronal-specific nuclear protein antibodies. The mouse cDNA sequence for the Advillin gene was amplified from neonatal mouse trigeminal ganglia cDNA using primers containing the $\mathrm{T} 7$ promoter sequence. The sequences of the primers were as follows: AvilF, 5'-CTGCCATTGTGCGAATCACC-3'; AvilB, 5'-GCGTAATACGACTCACTATAGGGCGAGAACATGCTGTGGCACATGG$3^{\prime}$. In vitro transcription was then performed from the PCR-amplified template using T7 RNA polymerase (Roche, Indianapolis, IN) with Digoxigenin-UTP (Roche) for the synthesis of the antisense probe for Advillin mRNA. In situ hybridization was performed according to standard methods (Hodge et al., 2007).

For the immunostaining combined with in situ hybridization, in situ hybridization was performed as described above. After the development of the in situs, the sections were washed in PBS and blocked in PBS containing $5 \%$ goat serum and $0.1 \%$ Triton X-100 (H-PHT) for $2 \mathrm{~h}$, followed by incubation with anti-neuronal-specific nuclear protein $(\mathrm{NeuN})$ antibody (1:1000; Chemicon, Temecula, CA) and detected by Alexa ${ }^{568}$-labeled anti-mouse IgG (1:400; Invitrogen, Eugene, OR).

Alkaline phosphatase staining and costaining with anti-protein gene product 9.5 antibodies. Tissue sections were collected with a cryostat at 20-30 $\mu \mathrm{m}$ thickness. The sections were postfixed with $4 \%$ PFA/PBS at room temperature for $1 \mathrm{~h}$, followed by incubation at $65^{\circ} \mathrm{C}$ for $4 \mathrm{~h}$ in PBS. For the detection of alkaline phosphatase activity, they were rinsed with wash buffer $(0.1 \mathrm{~m}$ Tris- $\mathrm{HCl}, \mathrm{pH} 7.5,0.1 \mathrm{M} \mathrm{NaCl})$ and then incubated in developing buffer [1:200 nitroblue-tetrazolium-chloride (NBT)/5bromo-4-chlor-indolyl-phosphate (BCIP) stock solution (Roche), $0.1 \mathrm{M}$ Tris- $\mathrm{HCl}$, $\mathrm{pH}$ 9.5, $0.1 \mathrm{M} \mathrm{NaCl}, 5 \mathrm{~mm} \mathrm{MgCl}_{2}$ ]. The reaction was stopped by washing in PBS three times.

For immunostaining combined with chromogenic alkaline phosphatase (AP) staining, AP staining was performed as described above. Sections were then incubated with anti-protein gene product 9.5 (PGP9.5) antibody (1:1000; UltraClone, Isle of Wight, UK) at $4^{\circ} \mathrm{C}$ overnight and detected with Alexa ${ }^{488}$-labeled anti-rabbit IgG (1:400; Invitrogen).

For immunostaining combined with fluorescent red AP staining, the sections were fixed in 4\% PFA/PBS solution and heat-inactivated in PBS as described above. They were then processed for immunofluorescence staining with anti-PGP9.5 antibody. Afterward, the sections were washed in AP-wash buffer (0.1 м Tris-HCl, pH 8.0, 0.1 м NaCl, 10 mm MgCl2) twice, followed by the development of fluorescent red color, which was performed by incubation with fast red solution (Roche).

In vitro culture of trigeminal neurons. Postnatal day 1 (P1) neonatal mice were killed, and their trigeminal ganglia were dissected out. Dissociated trigeminal neurons were cultured on laminin-coated glass coverslips in F12 supplemented with N3, glucose, $0.5 \%$ FBS, and $100 \mathrm{ng} / \mathrm{ml}$ NGF (Wang et al., 1999). After $24 \mathrm{~h}$, cultures were fixed stained with $2 \mathrm{H} 3$ anti-neurofilament antibody (1:200; Developmental Studies Hybridoma Bank, University of Iowa, Iowa City, IA). Images were acquired with an HR Axiocam (Zeiss, Thornwood, NY). The lengths of axons were mea- sured using MetaMorph software. $p$ values were calculated with Student's $t$ test.

Electrocauterization of vibrissal follicles. P1 neonatal mice were anesthetized by hypothermia plus isofluorane inhalation, and the whiskers on the right whisker pads were pulled out with forceps. The electrocauterization was performed as described previously (Van der Loos and Woolsey, 1973; Yamakado, 1999; Datwani et al., 2002; Rebsam et al., 2005). The pups were recovered and returned back to their home cage. They were killed and analyzed at P7.

Cytochrome oxidase staining. Cytochrome Oxidase (CO) staining was performed as described previously (Li et al., 1994). Briefly, the 4\% PFAfixed, frozen sections were washed in $0.1 \mathrm{~m}$ phosphate buffer, $\mathrm{pH} 7.5$, three times and incubated in developing solution $\left[6 \mathrm{mg} / \mathrm{ml} \mathrm{3,3^{ \prime } -}\right.$ diaminobenzidine tetrahydrochloride (Sigma, St. Louis, MO), 0.27 $\mathrm{mg} / \mathrm{ml}$ cytochrome $c, 50 \mathrm{mg} / \mathrm{ml}$ sucrose in $0.1 \mathrm{M}$ phosphate buffer, $\mathrm{pH}$ 7.5] at $37^{\circ} \mathrm{C}$ overnight. Images were acquired with an HR Axiocam (Zeiss). The areas of row $\mathrm{C}$ and row D (see Fig. 8) were measured using MetaMorph software. $p$ values were calculated with Student's $t$ test $(n=4)$.

\section{Results \\ Expression pattern of Advillin mRNA in the developing mouse nervous system}

Using in situ hybridization analysis, we found that Advillin mRNA can be detected in all sensory ganglia, including trigeminal (V), facial (VII), vestibulocochlear (VIII), glossopharyngeal (IX), vagus (X), and DRG (Fig. $1 A$ ) (supplemental Fig. S1, available at www.jneurosci.org as supplemental material). In TG, its expression begins at embryonic day 11.5 (E11.5) in a few scattered cells and appears in many cells at E12.5. These time points follow the initial axon outgrowth of newly born neurons toward the facial primordia, which happens at E10.5. The level of the expression increases during embryonic stages, reaching its maximum level at E16.5, which is maintained afterward (Fig. $1 B, D$ ). In DRG, the expression was clearly detected at E12.5, and the increase in Advillin mRNA follows a similar time course as that in TG (Fig. $1 C, D$ ). In addition to all craniofacial sensory ganglia, Advillin mRNA is also found in the neurons of the mesencephalic trigeminal nuclei (Me5), which consists of neural crest-derived proprioceptive sensory neurons innervating the masseter muscles (for review, see Lazarov, 2002). Additionally, Advillin mRNA is expressed in Mo5 motoneurons (supplemental Fig. S1, available at www.jneurosci.org as supplemental material). Aside from the above mentioned sensory and Mo5 neurons, our in situ hybridization experiments did not detect any Advillin signal in any other part of the brain or spinal cord (Fig. $1 A$ ) (data not shown). Furthermore, the peripheral sympathetic ganglia also do not express Advillin mRNA either (supplemental Fig. S2, available at www.jneurosci.org as supplemental material). Thus, Advillin is a specific marker for sensory neurons in the nervous system (with the exception of Mo5 motoneurons).

To confirm that Advillin is selectively expressed in postmitotic sensory neurons, but not in progenitor cells, we performed immunostaining with anti-NeuN antibody (a pan-neuronal marker) (Mullen et al., 1992) after the in situ hybridization of the Advillin probe to tissue sections from $\mathrm{P} 0$ animals (Fig. 1E). Essentially all Advillin-expressing cells are positive for NeuN immunoreactivity at birth. Also, all NeuN-positive cells are positive for Advillin mRNA. By performing a similar "two-color" immunostaining over in situ experiments in embryos, we found that, at E12.5, $42.6 \pm 2.0 \%$ of TG and $36.0 \pm 6.0 \%$ DRG (postmitotic) neurons are expressing Advillin. At E14.5, this number reaches to $86.7 \pm 1.0$ and $82.4 \pm 4.5 \%$ for TG and DRG neurons, respectively. By E16.5, almost all sensory neurons become Advillin positive $(97.7 \pm 1.0 \%$ for $\mathrm{TG}$ and $93.8 \pm 1.8 \%$ for DRG). Advillin 
expression in all somatic sensory neurons lasts into adulthood. In the next set of experiments, we focused our analyses solely on TG and DRG neurons.

\section{Generation of Avil-hPLAP mice}

The results shown above indicate that the Advillin locus can be used for genetic labeling of all somatosensory neurons and their projections. We constructed a targeting vector in which the start ATG codon of the Advillin gene was replaced by the hPLAP gene (Fig. 2). hPLAP has been used previously as a reliable axon tracer (Leighton et al., 2001). Knock-in mice were generated and their genotypes were confirmed by Southern blot (Fig. 2 B) and PCR (Fig. 2C). Heterozygous Avil-hPLAP mice did not show any obvious abnormality in their morphology or behavior. Homozygous mice do not express any Advillin mRNA as examined by in situ hybridization (data not shown) and thus are lacking Advillin protein. The number of homozygous offspring resulting from heterozygous crosses was much less than what is expected of a Mendelian ratio both at P0 (16.6\% homozygous - - , compared with $31.0 \%$ wild type, and $52.4 \%$ heterozygous $+/-$ mice; total, $n=187)$ and in adult (16.0\% - /-, compared with $32.7 \%$ wild type and $51.3 \%+/-$; total, $n=150)$. This indicates that approximately half of homozygous Avil-hPLAP mice are lethal at embryonic stages. The lethality is not caused by defects in the development of sensory neurons, because the dying mutant embryos were all younger than E10.5 (data not shown), a stage before the expression of Advillin begins in neurons. Because Advillin is also expressed in the placenta tissue (Marks et al., 1998), defects in the placenta may cause the early embryonic lethality but remains to be further studied. However, the survived homozygous animals were fertile (both males and females) and did not show any detectable abnormal behaviors.

To confirm the expression of hPLAP, we next performed AP staining on sections collected from heterozygous Avil-hPLAP embryos and neonatal mice. All sensory ganglia showed strong hPLAP activity (Fig. 3A) (data not shown). The expression of hPLAP followed the time course of endogenous Advillin expression. For example, in trigeminal ganglia, hPLAP activity was detected in subsets of neurons at E12.5. Both the number of hPLAP-positive neurons and the staining intensity increased gradually in all trigeminal neurons, reaching the maximum level by E16.5 (Fig. 3A). Similarly, we detected hPLAP activity in DRG at E12.5 onward (see Fig. 6).

\section{Using AP staining to visualize exquisite sensory endings in} Avil-hPLAP mice

We next examined whether hPLAP expressed from the Advillin locus can allow the visualization of the exquisite sensory endings
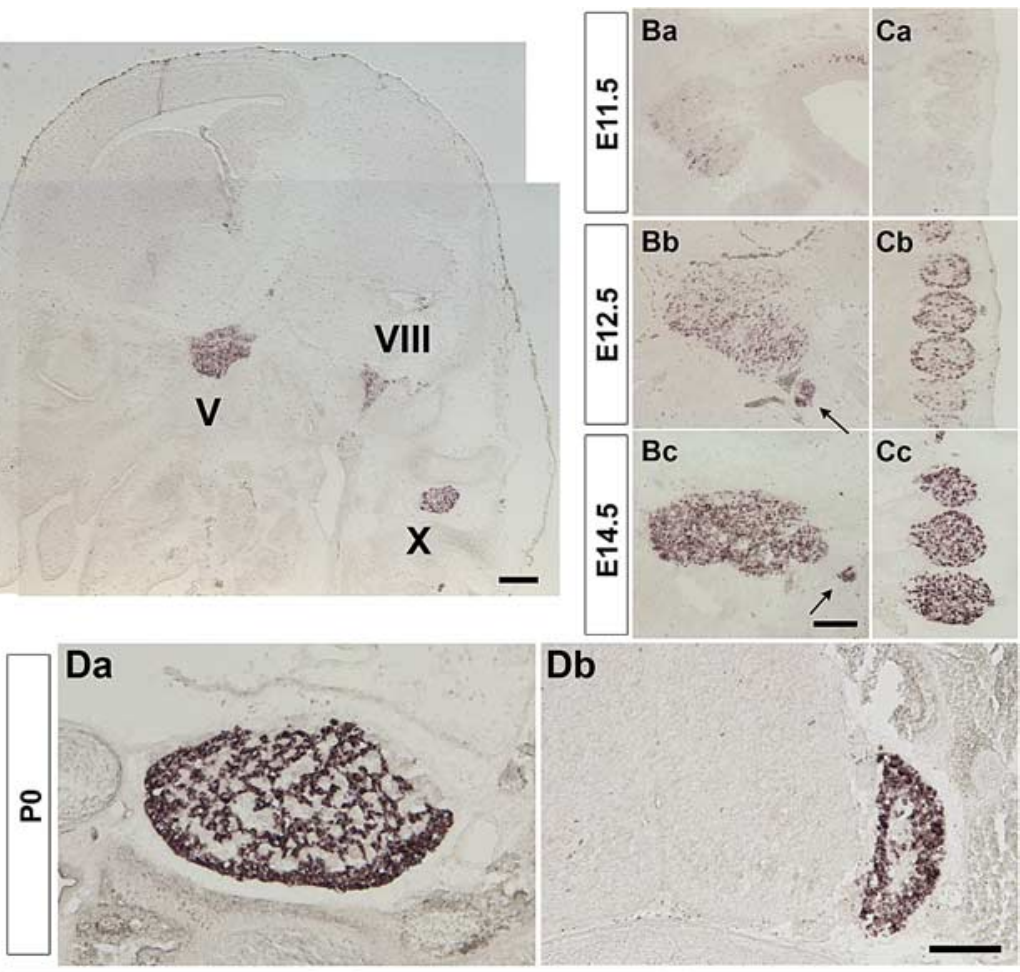

Db
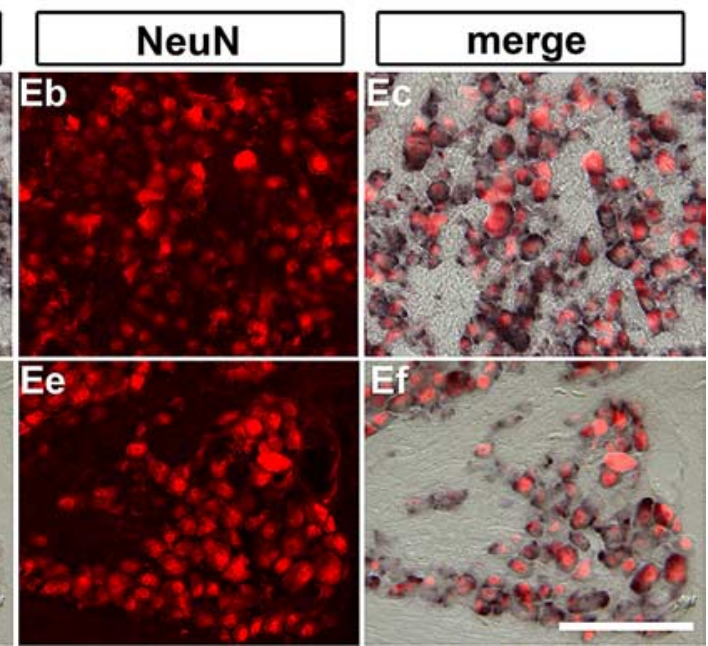

Figure 1. Advillin mRNA expression in the developing sensory ganglia. $A$, Transverse section of E14.5 embryonic head. Advillin is detected in all sensory ganglia, including trigeminal (V), vestibulocochlear (VIII), and vagus (X) ganglia but not in other areas such as cerebral cortex, thalamus, and cerebellum. Ba-Cc, Transverse sections of E11.5 (Ba, Ca), E12.5 (Bb, Ca), and E14.5 (BC, Ca) $\mathrm{TG}(\boldsymbol{B a}-\boldsymbol{B C})$ and DRG $(\boldsymbol{C} \boldsymbol{a}-\boldsymbol{C} \boldsymbol{c})$. The expression level of $A d v i l l i n$ increases during development. Arrows in $\boldsymbol{B} \boldsymbol{b}$ and $\boldsymbol{B} \boldsymbol{c}$ indicate the detected in the spinal cord. Ea-Ef, Coronal sections of P0 neonatal TG (Ea-Ec) and DRG (Ed-Ef). Advillin mRNA was detected by in situ hybridization, followed by immunostaining with pan-neuronal anti-NeuN antibody. All Advillin-positive cells were also NeuN positive, and all NeuN-positive neurons were Advillin positive. Scale bars: $A, B C, D C, 200 \mu \mathrm{m} ; \boldsymbol{E}, 100 \mu \mathrm{m}$.

formed by sensory axon termini within peripheral organs using the AP staining. Traditionally, these endings are detected by antiPGP9.5 antibody staining (Fundin et al., 1997a; Navarro et al., 1997; Rice et al., 1997). Note that anti-PGP9.5 labels all neurons, including sympathetic and motor neurons as well as sensory neurons (Schofield et al., 1995). In addition, we found that antiPGP9.5 antibody also stains blood cells, but the staining appears to be nonspecific. We wanted to compare AP staining with antiPGP9.5 immunofluorescence in Avil-hPLAP mice. For this purpose, we examined the sensory innervation of the large whiskers in detail. Whiskers are the primary tactile organs for mice. Each 

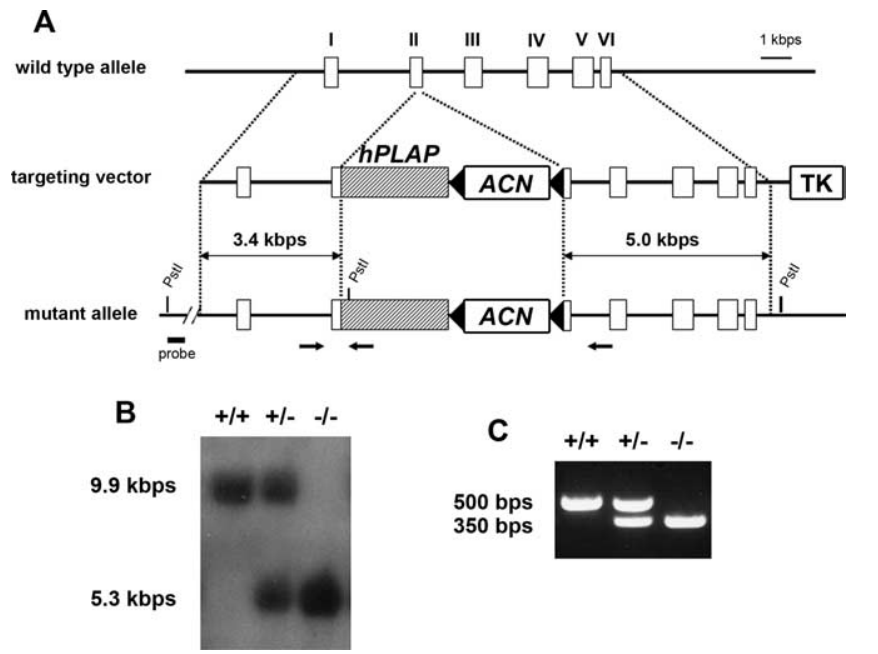

Figure 2. Targeted insertion of $h P L A P$ gene into the Advillin locus. $A$, Schematic representation of the gene insertion. $h P L A P$ gene with $A C N$ cassette was inserted at the translational start codon of Advillin gene. Exons are represented as white boxes. The thymidine kinase cassette is designated as TK. Arrows indicate the position of primers used for genomic PCR analysis. $\boldsymbol{B}$, Southern blot analysis of genomic DNA from wild-type, heterozygous, and homozygous mice. The 9.9 and $5.3 \mathrm{~kb}$ Pstl restriction fragments indicate wild-type and mutant allele, respectively. C, Genomic PCR analysis of the progeny. Wild-type and mutant alleles produced 500 and $350 \mathrm{bp}$ fragments, respectively.

whisker is innervated by at least six different types of mechanosensory trigeminal neurons that form morphologically distinct endings inside the follicular sinus complex (FSC) (Fundin et al., 1997b). Whisker pads from P7 Avil-hPLAP mice were sectioned and stained for hPLAP activity using the fluorescent fast red substrate. The same sections were also processed for immunofluorescence with anti-PGP9.5 antibody and Alexa ${ }^{488}$ conjugated secondary antibody. Although the fluorescent-red AP substrate generated higher background (Fig. 3B) (whereas NBT/ BCIP substrate did not), suffice it to say, all types of sensory nerve endings that are positive for anti-PGP9.5 signal could be detected by AP staining (Fig. 3B) (data not shown). Specifically, the superficial vibrissal nerves (SVNs) give rise to two types of touch neurons: the Merkel endings in the rete ridge collar (data not shown) and the transverse lanceolate endings in the inner conical body of FSC (Fig. $3 B a-d$, arrows). The deep vibrissal nerves (DVNs) supply four types of nerve endings: the longitudinal lanceolate endings (Fig. $3 B a-d$, arrowheads), the Merkel endings in the outer root sheath (Fig. $3 B a-h$, stars), the reticular endings (Fig. $3 B i-l$ ), and the Ruffini/spiny endings (Fig. $3 B m-p$ ) (Fundin et al., 1997b). All these endings were clearly visualized by AP staining. Nociceptive nerve fibers innervating the surface of the skin were also revealed by AP staining (data not shown). Importantly, motor axons from the facial nuclei and sympathetic nerves that also innervate the mystacial pads were positive for anti-PGP9.5 signal but were completely negative for hPLAP activity (Fig. 3C) (supplemental Fig. S2, available at www.jneurosci.org as supplemental material), again confirming the somatosensory-specific labeling of nerve endings at the peripheral target regions in AvilhPLAP mice.

Avil-hPLAP mice can also be used to visualize diverse types of sensory endings in various organs in adult mice. Several examples are shown in Figure 4. In the glabrous skin of the foot pad, AP staining revealed nociceptive endings that include free nerve endings (Fig. 4Ae, arrowhead) and the thermosensory Krause's end bulb (Fig. $4 A e$, open arrows), as well as mechanosensory endings that include Merkel endings (Fig. 4Ad, arrowheads), Meissner's corpuscles (Fig. 4Ac, arrow), and Pacinian corpuscles (Fig. 4Af), all in the dermal ridges and the interdigital pad. In the hairy skin isolated from the back of mice (dorsal skin), we observed hair and dermal innervations. Interestingly, it appeared that a randomly distributed subpopulation of hairs is innervated by sensory neurons (Fig. $4 \mathrm{Ag}$, dark arrows). This is because of the fact that many vellus hairs are not supplied by sensory axons (Fig. $4 A g$, open arrows). This observation is consistent with previous reports that vellus hair follicles formed after birth usually lack sensory innervation (Payne et al., 1991). In muscles, both the muscle spindle (Fig. $4 \mathrm{Ba}$ ) and the Golgi tendon (Fig. $4 \mathrm{Bb}$ ) innervation by proprioceptive DRG neurons could be clearly stained. Examples of the eyelids, cornea (Fig. 4C), and temporal mandibular joint innervation (Fig. $4 \mathrm{Db}$, arrowheads and open arrows) from trigeminal sensory neurons, as well as various taste buds innervation (Fig. $4 D$ ) from the 7th, 9th, and 10th ganglia neurons are also shown. In summary, Avil-hPLAP is a valuable tool for studying diverse sensory endings formed within distinct peripheral organs.

\section{Visualizing the development of peripheral sensory innervation using heterozygous Avil-hPLAP mice}

Taking advantage of the Avil-hPLAP mice, we decided to characterize the developmental process of peripheral sensory ending formation in specific organs. For example, although the adult whisker innervation has been studied in detail, the time courses of sensory projection and sensory ending formation during development have not been well characterized. We focused on the whisker and paw innervations for this study, because they represent hairy and glabrous skin, respectively. We stained the sections of developing mystacial pads from Avil-hPLAP embryos. At E12.5, when the whisker buds begin to emerge, a population of trigeminal axons forms a plexus underneath each bud (Fig. 5Aa, arrows), an observation consistent with previous findings (Van Exan and Hardy, 1980; Erzurumlu and Killackey, 1983; Davies and Lumsden, 1984; Scarisbrick and Jones, 1993). The tips of the axons form a bundle that accumulates and penetrates the perspective whisker follicle. This axon bundle later becomes the DVN. Notably, the surface skin between each whisker was not innervated at this point (Fig. 5Aa, arrowheads). This is not because of the lack of hPLAP expression at this stage in skinprojecting neurons, because anti-PGP9.5 staining, which labels all axons at this stage, gave the same result (supplemental Fig. S3, available at www.jneurosci.org as supplemental material). This result suggests that the onset of Advillin mRNA expression may be correlated with the engagement of sensory axons with their peripheral targets. By E14.5, DVN axons had further innervated alongside of the developing whisker FSC to the level of the ring sinus, forming a "basket" surrounding the follicles (Fig. 5Ab). However, no morphologically distinct mechanosensory endings have formed at this stage. Different from E12.5, however, cutaneous nociceptive axons could be observed underneath the skin at E14.5 (Fig. 5Ab, arrowhead). At E16.5 (a time when practically all sensory neurons express Advillin), Merkel endings at the ring sinus level had begun to appear in some FSCs, but no other forms of endings are formed at this stage (Fig. 5Ac, arrows). Moreover, there was no innervation at the outer and inner conical body level, which is supplied by the SVN at E16.5 (Fig. 5Ac, arrowheads). Soon after birth, SVN axons projected into the surface ridges of FSC and started to form the surface Merkel endings and the transverse lanceolate endings (Fig. 5Ad, arrows). This was also true for endings formed in the small whiskers located on the upper and lower lips (Fig. 5B). The formation of other nerve 
endings, such as longitudinal lanceolate endings, reticular endings, and Ruffini/spiny endings, happened in the first postnatal week and is completed by P7 (data not shown). The sequential formation of distinct types of sensory endings in the mouse whiskers we observed is similar to that previously described for ferret whiskers, which was revealed by the antiPGP9.5 staining (Mosconi and Rice, 1993).

In the footpad of the paws, sensory axons projected into the limb buds as fascicles that run in the middle of the developing digits at E12.5 (data not shown). By E14.5, a time when dermal ridges began to appear, sensory axons can be seen forming bundles underneath each ridge (Fig. 5Ca). Again, the lack of superficial skin projection is not attributable to the lack of Advillin expression in skin-innervating neurons at this stage, because anti-PGP9.5 staining showed very similar pattern as the AP staining (supplemental Fig. S3, available at www.jneurosci.org as supplemental material). Diffuse innervations of the entire glabrous skin of the digits were observed at P0. At this stage, Merkel endings and free nerve endings were apparent (Fig. $5 \mathrm{Cb}$ ), but other types of sensory endings (corpuscles) were formed much later in postnatal development and were completed by 2 weeks after birth (data not shown). Together, our results indicate the following: sensory neurons are engaged with developing whisker follicles and dermal ridges early in embryos; nociceptive projections into the superficial skin lag behind the mechanosensory innervation of whiskers; and many specialized touch sensory endings are differentiated after birth in the first and second postnatal week.

\section{Visualizing the development of sensory axon collateral projections into the brainstem and the spinal cord using heterozygous Avil-hPLAP mice}

The sensory information detected by the peripheral nerve endings of somatosensory neurons is transmitted to the brainstem and the spinal cord through their central axons. Again, taking advantage of the Avil-hPLAP mice, we studied the developmental time course of the central axon collateral projections from these sensory neurons.

TG (trigeminal) sensory neurons project to the principle trigeminal nucleus (Pr5) and three spinal trigeminal nuclei (Sp5) in the brainstem. The development of the trigeminal central collaterals has not been well documented. We stained the brainstem sections for hPLAP activity at several embryonic stages. At E12.5, the main central axons of TG neurons have formed the trigeminal tract alongside the hindbrain, and essentially no collaterals sprout into the central nuclei (Fig. $6 A a, A b)$. By E14.5, the majority of TG axons has not yet extended collaterals. However, branches from the mandibular TG neurons,

C
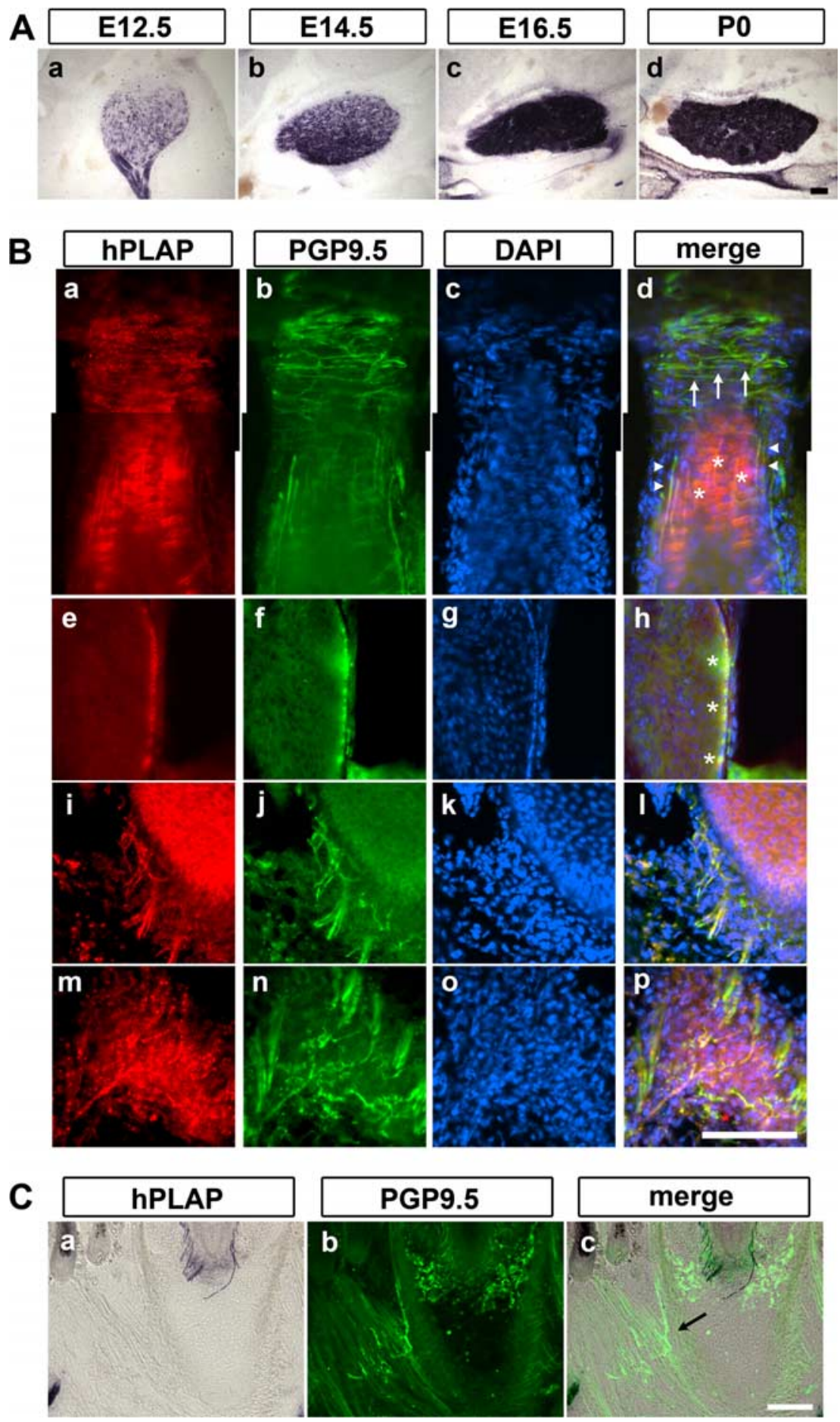

Figure 3. Trigeminal sensory innervation of whiskers visualized by AP staining in Avil-hPLAP mice. $A$, Coronal sections of E12.5, E14.5, E16.5, and P0 neonatal TG. hPLAP activity was detected at E12.5 onward, and the intensity reached the maximum at E16.5. B, Coronal sections of large vibrissa on mystacial pads from P7 Avil-hPLAP mice were costained for anti-PGP9.5 reactivity and for hPLAP activity using fast red as a substrate. All types of mechanosensory nerve endings, including transverse ( $\boldsymbol{B} \boldsymbol{a}-\boldsymbol{d}$, arrows) and longitudinal ( $\boldsymbol{B} \boldsymbol{a}-\boldsymbol{d}$, arrowheads) lanceolate endings, Merkel endings ( $\boldsymbol{B} \boldsymbol{a}-\boldsymbol{h}$, asterisks), reticular endings ( $\boldsymbol{B} \boldsymbol{i}-\boldsymbol{I})$, and Ruffini endings $(\boldsymbol{B} \boldsymbol{m}-\boldsymbol{p})$, are costained. $\boldsymbol{C}$, Coronal sections containing muscles at the bottom of the whiskers were stained for hPLAP activity, followed by immunostaining with anti-PGP9.5 antibody. Facial motor axons innervating muscles were negative for hPLAP activity (arrow). Scale bars, $100 \mu \mathrm{m}$.

facial (VII), glossopharyngeal (IX), and vagus (X) ganglia neurons can be detected projecting into the hindbrain (Fig. 6Ad). Major axonal collateral in-growth is seen at approximately E15.5-E16.5 (Fig. 6Ae,Af) (data not shown). These collaterals 

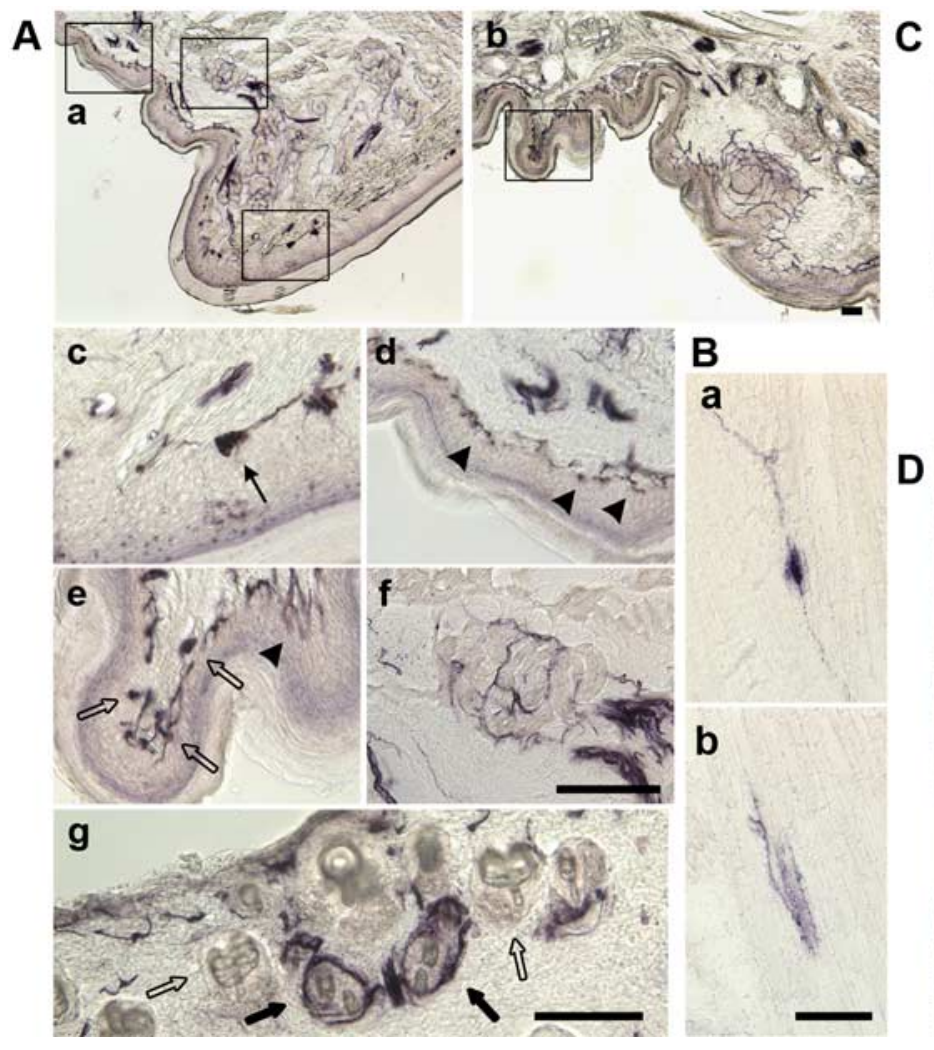

C
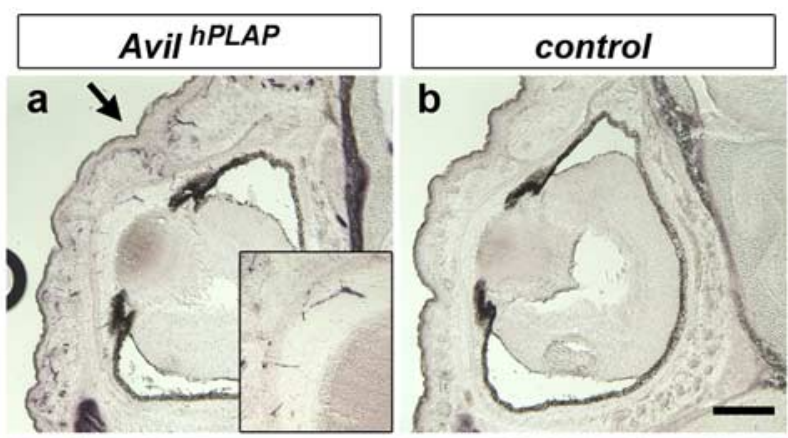

D

b

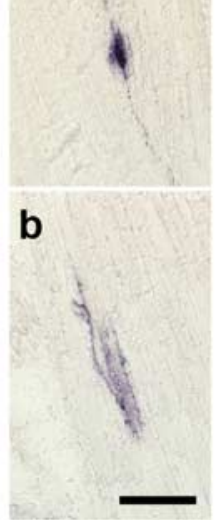

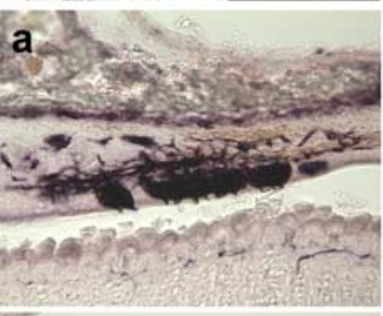

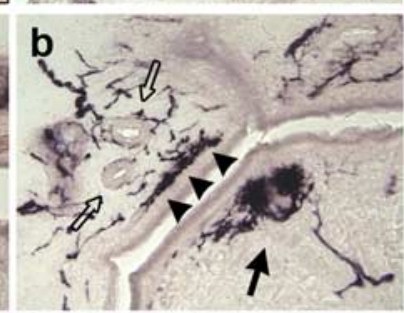

C
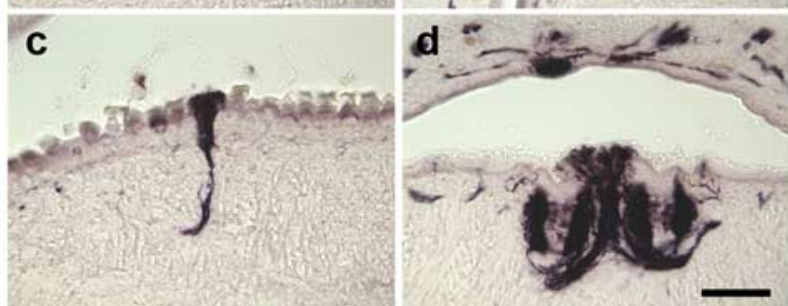

Figure 4. Diverse sensory endings in various tissues revealed by AP staining in Avil-hPLAP mice. $A$, Cutaneous skin innervation. Various types of nociceptive and mechanosensory endings are clearly visualized in glabrous skin on the forepaw from adult mice $(\boldsymbol{A} \boldsymbol{a}-\boldsymbol{f})$. $\boldsymbol{A} \boldsymbol{a}, \boldsymbol{A b}$, Lower-magnification pictures. $\boldsymbol{A c}-\boldsymbol{f}$, Higher-magnification pictures from $\boldsymbol{A} \boldsymbol{a}$ and $\boldsymbol{A b}$ (boxes in $\boldsymbol{A a}$ and $\boldsymbol{A b})$ show hPLAP-positive Meissner's corpuscles (Ac, arrow), Merkel endings ( $\boldsymbol{A d}$, arrowheads), Krause's end bulbs (Ae, open arrows), free nerve endings (Ae, arrowheads), and Pacinian corpuscles (Af). In hairy skin, hPLAP-positive axons densely innervate guard hair follicles (closed arrows) but not in a subset of vellus hairs (open arrows) (Ag). $\boldsymbol{B}$, Proprioceptive innervation of muscle spindles (Ba) and Golgi tendons $(\boldsymbol{B} \boldsymbol{b})$ are visualized in PO neonatal skeletal muscles. $\boldsymbol{C}$, Sensory innervation of cornea. hPLAP-positive axons are found in cornea at PO ( $\boldsymbol{C}$, inset) but not in control mice ( $\boldsymbol{C}$ ). A boundary between the upper and lower lids is shown by an arrow, where there is dense innervation by hPLAP-positive axons. Inset, Higher-magnification of $C a$. $D$, All types of taste buds are innervated by the Advillin-positive axons. Facial, glossopharyngeal, and vagus nerves innervating the taste buds in upper soft palate ( $\boldsymbol{D a}$ ), filliate ( $\boldsymbol{D} \boldsymbol{b}$, closed arrow), fungiform ( $\boldsymbol{D} \boldsymbol{c})$, and circumvallate papillae ( $\boldsymbol{D} \boldsymbol{d})$ are positive for hPLAP. Trigeminal mandibular axons innervating temporomandibular joint form Ruffini endings (arrowheads) and Golgi-Mazzoni corpuscles (open arrows), which are also clearly visualized. Scale bars, $100 \mu \mathrm{m}$.

gradually become fasciculated after birth (Fig. 6Ag,Ah), and the fascicles are obvious at P7 (Fig. 6Ai). Collaterals from sensory neurons in the facial (VII), glossopharyngeal (IX), and vagus (X) ganglia can also be seen innervating the nucleus of the solitary tract (Fig. 6Ag-Ai).

DRG neurons project central collaterals into the spinal cord. At E12.5, the main central axons form the dorsal root entry zone aligning with the dorsal margin of the spinal cord, and no collaterals have extended into the spinal cord (Fig. 6Ba). By E14.5, proprioceptive (Ia) axonal collaterals can be seen projecting ventrally and have reached the middle part of the spinal cord (Fig. $6 \mathrm{Bb}$, arrow). In addition, mechanosensory collaterals innervating lamina III and IV also begin to sprout into the spinal cord at this stage (Fig. $6 \mathrm{Bb}$, arrowhead). By E16.5, many hPLAP-positive axons can be seen throughout lamina I-IV (Fig. $6 \mathrm{Bc}$ ). Moreover, the Ia fibers innervating motoneurons have reached to the lamina VIII at this stage (Fig. $6 \mathrm{Bc}$, arrow), and those innervating ventral interneurons begin to project toward the medial part of the ventral spinal cord (Fig. $6 B c$, arrowhead). The collaterals innervating motoneurons and ventral interneurons are further arborized and ramified at $\mathrm{P} 0$. The time course of central collateral development observed with AP staining is consistent with previous dye tracing studies in fixed rat embryos (Mirnics and Koerber, 1995; Erzurumlu et al., 2006). Thus, Avil-hPLAP mice line is a useful and convenient tool for studying sensory connectivity and sensory circuit formation inside the brain.

\section{Regenerative axonal outgrowth is impaired in} Advillin-deficient neurons

Advillin is an actin binding protein, and previous experiments have shown that transfecting a dominant-negative form of Advillin into DRG neurons moderately reduced their axon length (Ravenall et al., 2002). However, we did not detect any developmental defects in axon growth or projection patterns in Avil-hPLAP homozygous mice by AP staining (data not shown) (Fig. 8), indicating that Advillin function is dispensable for somatosensory neuron development. We next examined the regenerative axon outgrowth in vitro of Advillin-deficient sensory neurons. Trigeminal sensory neurons isolated from P1 control or Avil-hPLAP homozygous mice were cultured at low density on laminin for $24 \mathrm{~h}$ in the presence of NGF. The cultures were then fixed and stained with anti-neurofilament antibody to reveal the axonal morphology. Indeed, we found that the in vitro axonal regrowth is significantly shorter in the absence of Advillin protein (Fig. 7). Quantitative analyses showed that the average total axon length was $2282.7 \pm 354.7 \mu \mathrm{m}(n=37)$ for wild-type neurons, 2497.6 $\pm 429.7 \mu \mathrm{m}(n=33)$ for Avil-hPLAP heterozygous, and only $1316.8 \pm 235.3 \mu \mathrm{m}(n=43)$ for Avil-hPLAP homozygous neurons. The average length of the longest axon was $449.2 \pm 39.6$ $\mu \mathrm{m}$ for wild-type, $489.7 \pm 33.2 \mu \mathrm{m}$ for heterozygous, and $282.7 \pm$ $23.7 \mu \mathrm{m}$ for homozygous mutant neurons. These results indicate that although Advillin protein is not required for development and maintenance of the sensory neuron axons, it is important for regenerative axon growth. We also quantified the total number of axon 


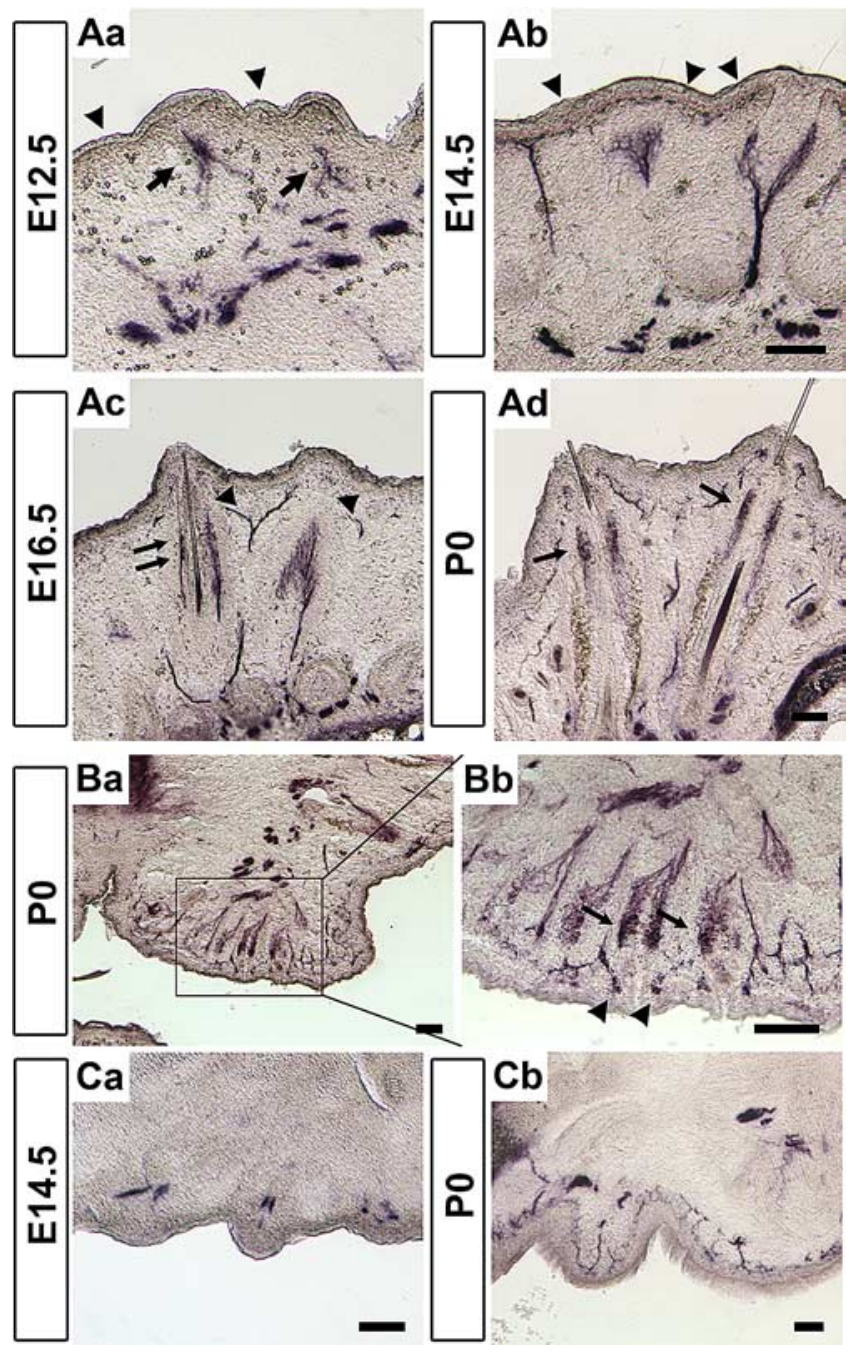

Figure 5. Sequential development of whisker- and skin-innervating somatosensory nerve endings. $\boldsymbol{A}$, Coronal sections of developing mystacial pads. At E12.5 (Aa) and E14.5 (Ab), most axons were found at the developing FSC and form a plexus, which are presumptive DVN axons (arrows), whereas the nociceptive axon tips are first found at E14.5 at the surface skin between each whisker (arrowheads). At E16.5, Merkel endings at the ring sinus level are first observed (arrows). SVN axons are not yet found at this stage ( $\boldsymbol{A C}$, arrowheads). At P0, Merkel endings and transverse lanceolate endings, but not other type of endings, are observed ( $\boldsymbol{A d}$, arrows). $\boldsymbol{B}$, Trigeminal axons innervating the small whiskers are detected at P0. Mechanosensory Merkel endings, transverse and longitudinal lanceolate endings (arrows), as well as nociceptive circumferential free endings (arrowheads) are observed. C, Transverse sections of developing forelimbs. By E14.5, the sensory axons reach their targets and form a plexus underneath the presumptive dermal ridges $(\mathbf{C a})$. At P0, the innervations are distributed to cover the entire skin but have not formed specialized nerve endings $(\boldsymbol{C b})$. Scale bars, $100 \mu \mathrm{m}$.

branches, which were found to be $8.41 \pm 1.66$ (wild type), $7.64 \pm$ 1.37 (heterozygous), and $5.28 \pm 1.03$ (mutant) branches per neuron. These values, however, are not significantly different (Student's $t$ test).

\section{Defect in remodeling of trigeminal central projections after} whisker cauterization in the Advillin-deficient mice

We also examined the potential role of Advillin protein in neonatal plasticity of sensory projections. The central axons from trigeminal neurons innervating the whiskers form modular synapses known as "barrelettes" in the hindbrain. The pattern of the barrelettes precisely replicates the pattern (and the number) of the whiskers and can be visualized by the CO staining method. It is known that the barrelettes structures are still plastic at the early postnatal stages, because cauterization of whiskers in neonatal mice pups (but not in animals older than 1 week of age) results in both the disappearance of those barrelettes representing the lesioned whiskers and the compensatory expansion of neighboring barrelettes. However, the molecular mechanisms underlying such lesion-induced structural plasticity are primarily unknown at present. Because Advillin protein possesses actin cytoskeleton remodeling activity, we therefore examined whether Advillin is required for such lesion-induced reorganization of the barrelettes.

We performed unilateral electrocauterization of row C whiskers in P1 heterozygous and homozygous Avil-hPLAP pups and analyzed the barrelettes pattern at P7 using both $\mathrm{CO}$ staining and AP-staining method. On the control uninjured side, CO staining revealed the five rows of whisker-related patterns in $\operatorname{PrV}, \mathrm{Sp} 5 \mathrm{i}$ (Fig. 8A,E), and $\mathrm{Sp} 5 \mathrm{c}$ nuclei (data not shown). There are no differences between heterozygous and homozygous Avil-hPLAP mice under normal conditions (Fig. 8I,M). Similarly, AP staining of sections adjacent to the CO-stained sections showed that the innervation of the trigeminal central axons and the patterns are indistinguishable between the two genotypes, again confirming that Advillin is not required for the normal development of trigeminal central projection (Fig. $8 B, F, J, N$ ). Note that "patches" of intense AP staining correlate with the barrelettes revealed by $\mathrm{CO}$ staining. However, because hPLAP labels the entire axons, not just the synapses, the boundaries between the patches are not as clear as the CO staining.

On the side where whiskers in row $\mathrm{C}$ were cauterized, in the heterozygous mice, $\mathrm{CO}$ staining showed that barrelettes representing row $\mathrm{C}$ disappeared, whereas barrelettes of row $\mathrm{B}$ and row $\mathrm{D}$ expanded. These results are consistent with previous studies (Van der Loos and Woolsey, 1973; Datwani et al., 2002; Rebsam et al., 2005). In contrast, in cauterized Avil-hPLAP homozygous mice, $\mathrm{CO}$ staining revealed that some of the row-C barrelettes persisted, and the neighboring rows did not appear to expand as much (Fig. $8 D, H, L, P$ ). This phenotype can be quantified by measuring the central areas representing the intact row $\mathrm{D}$ versus the cauterized row C (and expressed as the D/C ratio) (Schlaggar et al., 1993). We found that the whisker-lesion significantly increased $\mathrm{D} / \mathrm{C}$ ratio in heterozygous mice but only mildly affected $\mathrm{D} / \mathrm{C}$ ratio in homozygous mice (Fig. $8 Q, R$ ). These data indicate that the expansion of the unaffected barrelettes requires Advillin function. Using AP staining on sections adjacent to the COstained sections, we found that: (1) axons were still present even in the regions where there were no longer barrelettes after the cauterization (same for both genotypes); and (2) the intense purple patches of central axon termini in the reorganized region in heterozygous mice mostly disappeared (Fig. $8 C, K$ ), whereas the patches remained similarly (comparable with the unlesioned side) in the homozygous mice (Fig. $8 G, O$ ). This result implicates that Advillin function is required in sensory neurons for the axon remodeling processes after peripheral injury in neonates. Note that the differences in the central patterns between the heterozygous and homozygous mice were not a result of the differences in the peripheral lesions, because AP staining of the whisker pads showed equal extent of denervation of the cauterized whiskers in heterozygous and homozygous pups (supplemental Fig. S4, available at www.jneurosci.org as supplemental material). Similar results were obtained when performing the cauterization at P3 and examining the hindbrain at P7 (data not shown). These findings strongly suggest that efficient neonatal reorganization and structural plasticity of the whisker-related central patterns require the activity of Advillin proteins. 

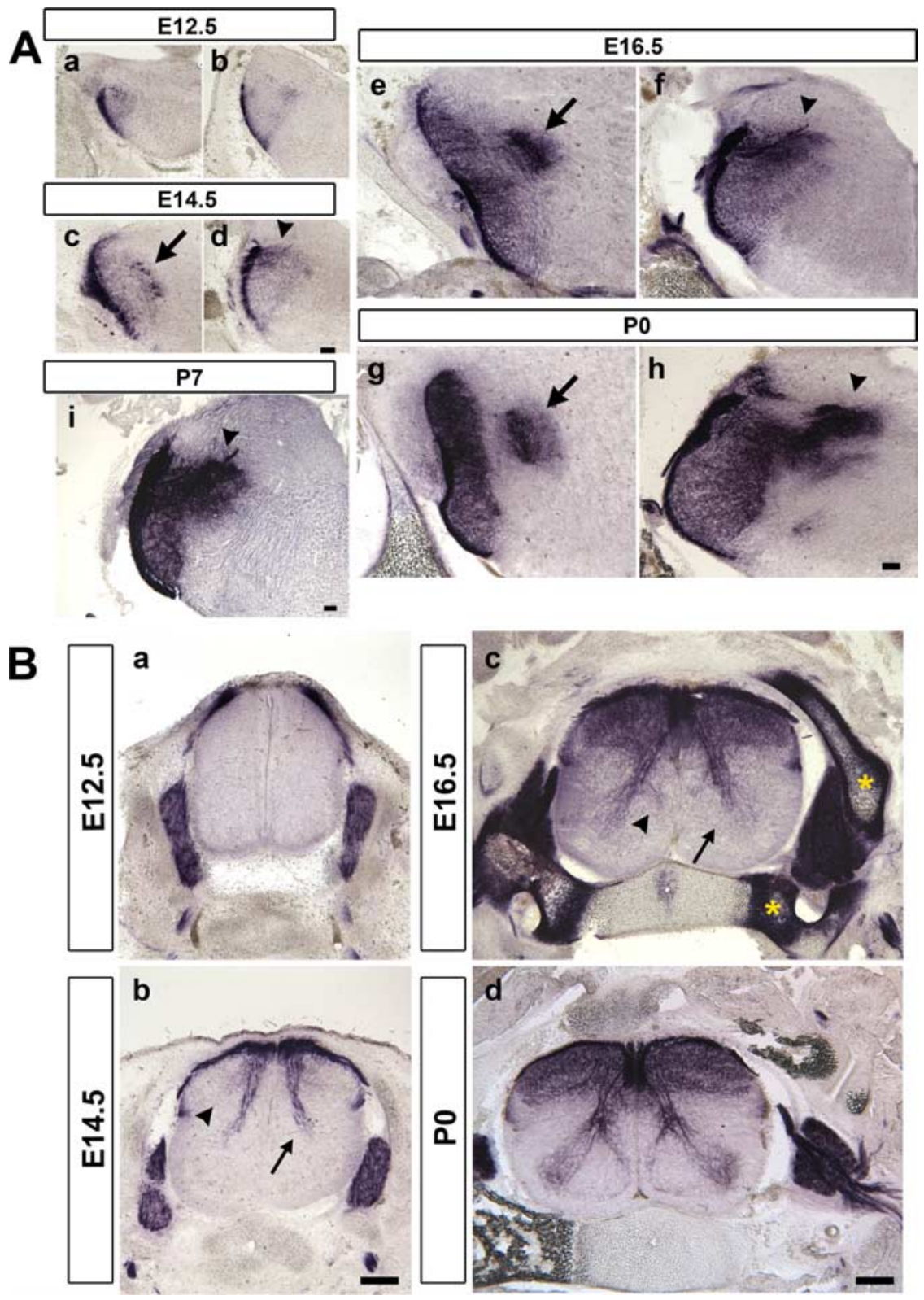

Figure 6. Central innervation of TG and DRG neurons. $\boldsymbol{A}$, Coronal brainstem sections at $\operatorname{Pr} 5(\boldsymbol{a}, \boldsymbol{c}, \boldsymbol{e}, \boldsymbol{g})$ and $\operatorname{Sp5}(\boldsymbol{b}, \boldsymbol{d}, \boldsymbol{f}, \boldsymbol{h}, \boldsymbol{i})$ level were stained by $\mathrm{hPLAP}$ activity. Very few trigeminal axons innervate the central trigeminal nuclei until E14.5. Extensive trigeminal collateral projections can be seen at E16.5. The pioneer innervation of facial, glossopharyngeal, and vagus nerves into the solitary tract nucleus are found at E14.5 onward (arrowheads). Arrows indicate the hPLAP signal in M05 motoneurons, which express Advillin mRNA. B, Coronal spinal cord sections. Proprioceptive la fibers (arrows) and cutaneous mechanosensory axons innervating layer III/IV (arrowhead) are first found at E14.5 and precede the development of nociceptive innervations (Bb). By E16.5, la fibers form a branch to project to the medial part of spinal cord (BC, arrowhead). Asterisks indicate nonspecific heat-stable alkaline phosphatase activity observed in cartilages. The mature pattern of $D R G$ central projection is established at P0 (Bd). Scale bars: $\boldsymbol{A}, 100 \mu \mathrm{m} ; \boldsymbol{B}, 200 \mu \mathrm{m}$.

\section{Discussion}

We studied in detail the expression pattern of Advillin in the developing mouse nervous system. We found that it is almost exclusively expressed by craniofacial and dorsal root ganglia sensory neurons. The only two exceptions are the Me5 mesencephalic trigeminal neurons (which are proprioceptive sensory neurons) and Mo5 trigeminal motor neurons, both located inside the hindbrain. We used this genetic locus to express an axonal tracer protein, hPLAP. Avil-hPLAP mice allowed us to visualize, at a high resolution, the exquisite sensory endings in diverse peripheral targets, as well as the developmental process of both peripheral and central axonal projections. We found that both peripheral and central targets are innervated by sensory neurons in an ordered manner. Finally, we provide evidence that Advillin protein functions in sensory axon remodeling and regeneration.

\section{Somatosensory neuron-specific expression of Advillin mRNA}

Advillin was originally identified as a member of the gelsolin family of actin-binding proteins (Marks et al., 1998). A dominantnegative form of Advillin was shown to reduce neurite growth of rat DRG neurons in culture (Ravenall et al., 2002). The in vivo expression pattern of Advillin mRNA, however, was not consistent among these previous studies. We showed that Advillin is expressed by craniofacial and dorsal root ganglia neurons, Me5 proprioceptive neurons, and Mo5 motoneurons but not expressed in any other cells in the nervous system, such as cerebral cortex or sympathetic ganglia neurons. The transcriptional mechanism underlying such restricted patterns of Advillin gene expression is currently unknown. The Advillin gene is located on chromosome 10 in mice and chromosome 12 in humans. In both genomes, Advillin is closely flanked by other genes: CTDSP2 is $1.8 \mathrm{~kb}$ upstream to Advillin, whereas METTL1 is $21 \mathrm{~kb}$ downstream to Advillin in mouse genome. A computational analysis of putative transcription binding sites in the intergenic DNAs in the human genome revealed that only one candidate, the site for transcription factor FOXA2 (University of California Santa Cruz Genome Bioinformatics, http://genome.ucsc.edu/), also called hepatocyte nuclear factor 3- $\beta$ (HNF3$\beta$ ), appears near the transcription initiation site. This FOXA2-binding site is conserved between mouse and human. However, HNF3- $\beta$ / FOXA2 is not expressed in TG and DRG throughout the development (Rausa et al., 1997), suggesting there are other transcription factors regulating the expression of Advillin. A previous study by Eng et al. (2004) showed $A d$ villin mRNA is reduced in Brn3a-null mice, suggesting the POU-domain transcription factor Brn3a may also control the expression of Advillin, although we did not identify any POU-domain factor binding site in the immediate genomic region adjacent to Advillin. It could well be that enhancer elements located distantly regulate Advillin expression.

\section{Physiological functions of Advillin in the somatic sensory system}

Gelsolin family proteins control actin organization by severing F-actin filament in a calcium ion-dependent manner and subsequently capping the severed ends. In vitro and in vivo analyses have revealed these proteins are involved in cell motility, exocy- 
tosis, phagocytosis, and apoptosis (for review, see Silacci et al., 2004). Indeed, previous in vitro studies presented a possible role of Advillin in neurite growth of DRG neurons (Ravenall et al., 2002). More recently, Advillin was shown to interact directly with a scavenger receptor, SREC-1, and such interaction/signaling led to the formation of neurite-like long processes in Neuro-2a cells (Shibata et al., 2004). However, the in vivo function of Advillin has not been tested to date.

We generated a line of knock-in mice in which the hPLAP gene replaced the start codon of the Advillin gene. In situ hybridization analysis using a probe against the Advillin coding region did not detect any signal in Avil-hPLAP homozygous mice, indicating that the mutant mice are null for both Advillin mRNA and protein (data not shown). Although 50\% of homozygous mice die during embryogenesis, the other $50 \%$ of Advillin mutant mice did not show any noticeable abnormality in development, growth, or behavior. Because half of the homozygous embryos die in the early embryonic stages, before E10.5, the lethality is unlikely caused by defects in the sensory systems. Advillin has been shown to be expressed in the placenta (Marks et al., 1998), and we speculate that dysfunction of the placenta may be a cause of this early embryonic lethality. In the surviving mice, the nerve projection pattern of TG and DRG sensory neurons are indistinguishable between homozygous and heterozygous AvilhPLAP mice (data not shown) (Fig. 8), indicating the Advillin is dispensable for neurite growth and axon guidance during development. Certain gelsolin family proteins were known to function as transcriptional cofactors in nuclear receptor signaling by forming a complex with monomeric actin, nuclear receptors themselves, and other transcriptional molecules (for review, see Archer et al., 2005). We therefore examined the expression pattern of major sensory neuron landmark genes, such as TrkA, TrpM8, TrpV1, and MEF2C (Tominaga et al., 1998; McKemy et al., 2002; Peier et al., 2002; Story et al., 2003; Chen et al., 2006) (H.H. and F.W., unpublished observation) and found they are all normally expressed in homozygous Avil-hPLAP mice (data not shown). It is interesting to note that gelsolin family proteins show significant similarities in their primary structures, and mice deficient for Villin, the closest relative of Advillin, do not show any apparent abnormalities (Pinson et al., 1998). Therefore, members of the gelsolin family may compensate for each other. This may explain the lack of phenotypes in the surviving Avil-hPLAP homozygous mice.

We did uncover a requirement for Advillin function in regenerative axon outgrowth and in the remodeling of central trigeminal axon innervations after whisker-lesion in the neonatal stages. There are many lines of evidence indicating that regenerative axon growth uses molecular mechanisms and signaling pathways different from developmental axon growth (for review, see Harel and Strittmatter, 2006; Rossi et al., 2007; Schwab and He, 2007). Perhaps the actin-binding and reorganizing activity of Advillin is important for efficient axon remodeling, although it is dispens-
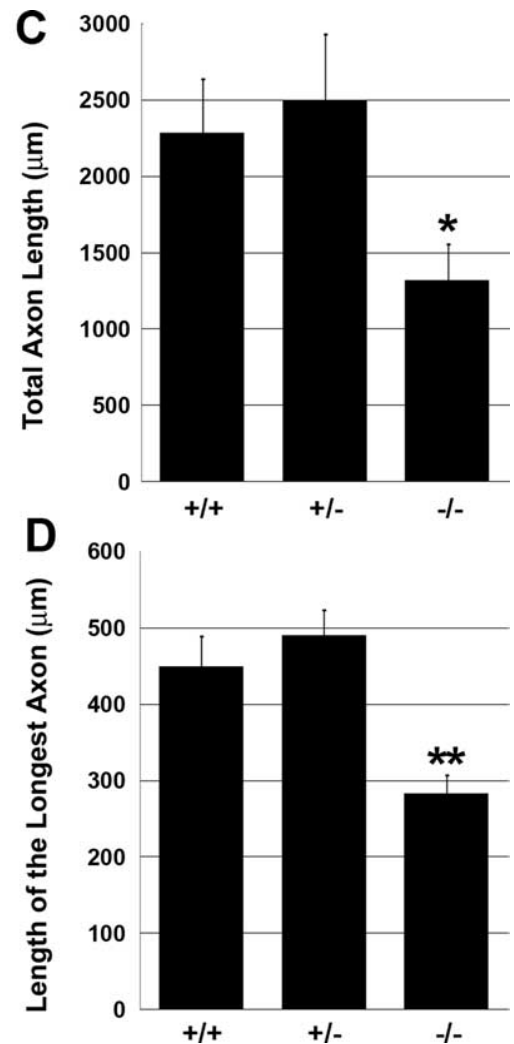

$+1+$

$+1$ shown to be upregulated by endoplasmic reticulum stresses (Wang et al., 1998). Considering axon severing represents a major stress to neurons, perhaps Advillin is required for some of the stress responses in TG and DRG neurons. We noted that the central axons appear more stable and less plastic after peripheral lesion in Advillin-deficient mice. In this respect, we speculate that inhibiting the activity of Advillin protein might be beneficiary for preventing the development of neuropathic pain because ectopic sprouting of axon termini in the dorsal horn of the spinal cord was implicated as one underlying mechanism of neuropathic pain (Woolf et al., 1992, 1995; Coggeshall et al., 1997).

\section{The development of sensory innervation in peripheral and central targets}

We took advantage of the Avil-hPLAP knock-in mouse to visualize the developmental process of sensory ending formation inside peripheral tissues, as well as the collateral formation in the CNS. In the trigeminal system, whisker follicles are "invaded" by TG sensory axons earlier than the superficial skin. TG axons are closely engaged with the newly formed whisker bud beginning at E12.5. TG axons grow and branch as the follicles are developing and maturing, but the formation of the morphologically distinct sensory endings happens at late developmental stages (after E16.5) and mostly during the first postnatal week. The trigeminal central collateral projections into $\operatorname{Pr} 5$ and Sp5 regions are rare at E14.5. The majority of axons enter into these regions between E16.5 and P0. After birth, TG collaterals are further fasciculated inside the hindbrain. Similarly, DRG neurons innervating the glabrous skin of the footpads engage with the budding dermal 

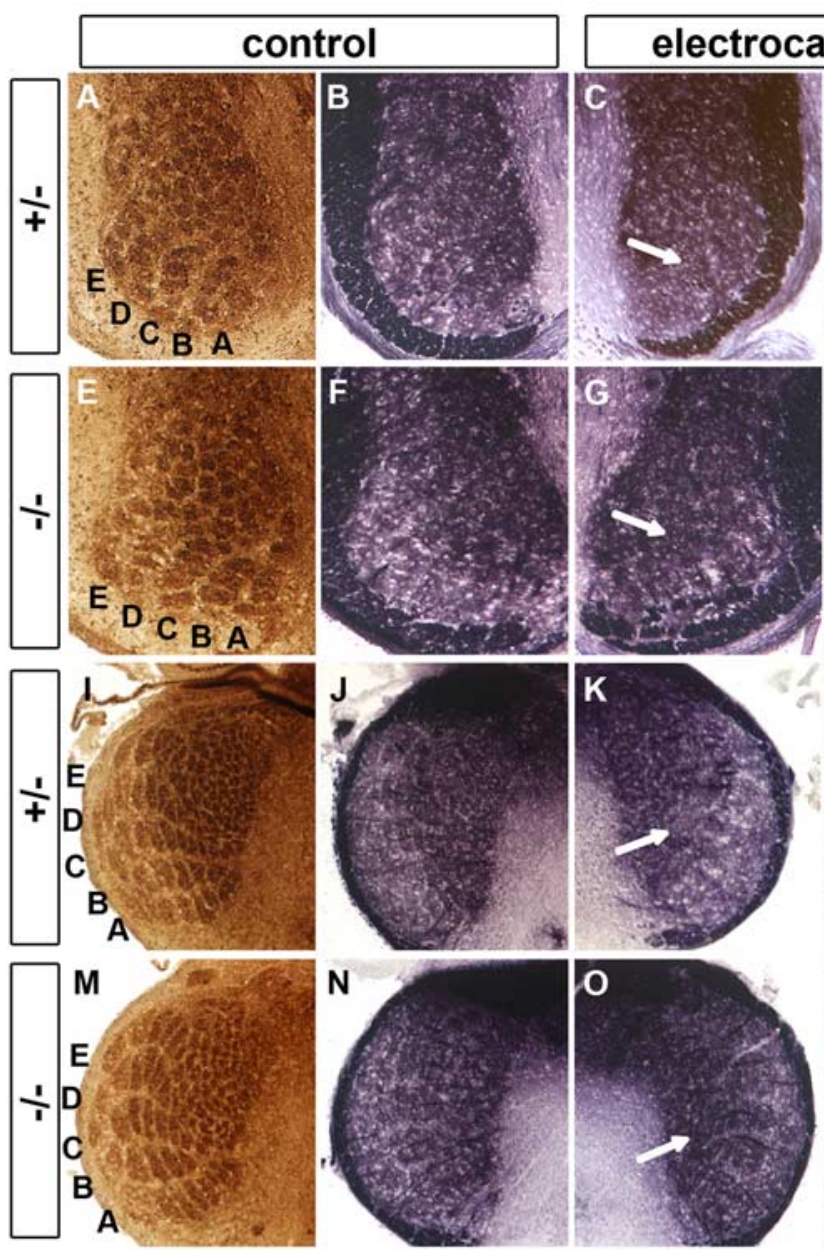

Q
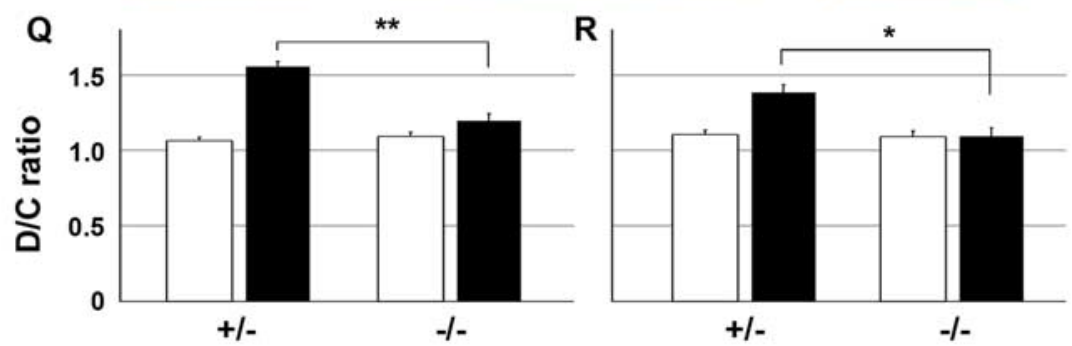

Figure 8. Reduced structural plasticity of whisker-related patterns in the hindbrain of the Avil-hPLAP homozygous mice. The row $C$ of whiskers was electrocauterized at P1. $\boldsymbol{A}-\boldsymbol{P}$, The PrV and Sp5i levels of hindbrain at P7 were sectioned at $20 \mu \mathrm{m}$ and stained for $C(\boldsymbol{A}, \boldsymbol{D}, \boldsymbol{E}, \boldsymbol{H}, \boldsymbol{I}, \boldsymbol{L}, \boldsymbol{M}, \boldsymbol{P})$ and AP activity $(\boldsymbol{B}, \boldsymbol{C}, \boldsymbol{F}, \mathbf{G}, \boldsymbol{J}, \boldsymbol{K}, \boldsymbol{N}, \mathbf{O})$. Arrows indicate the position of row $\mathbf{C}$. Scale bar, $100 \mu \mathrm{m}$. $\boldsymbol{Q}, \boldsymbol{R}$, Quantification of the lesion-induced plasticity of whisker-related patterns at the $\operatorname{PrV}(\mathbf{Q})$ and $\operatorname{Sp} 5 \mathrm{i}(\boldsymbol{R})$ levels. The areas of row Cand D were measured using MetaMorph software, and the D/C ratio was calculated as described in Materials and Methods. ${ }^{*} p<$ $0.01,{ }^{* *} p<0.005$, compared with electrocauterized heterozygous data. The error bars represent \pm SEM.

ridges in early embryos, form Merkel endings beginning at E16.5 (data not shown), and develop other specialized corpuscles after birth. The central DRG collaterals innervate the spinal cord in a sequential manner according to their sensory modalities, with proprioceptive axons projecting into the CNS first, followed by mechanosensory and nociceptive axons. Our results indicate that although sensory neurons are engaged with their peripheral targets early in embryos, the formation of specialized sensory endings, as well as the assembly of sensory circuits, stretches over a long period, even until after birth. We speculate this lengthy process reflects the progressive differentiation of the peripheral targets and that the subtype specification and functional maturation of sensory neurons may be regulated by the peripheral targets.

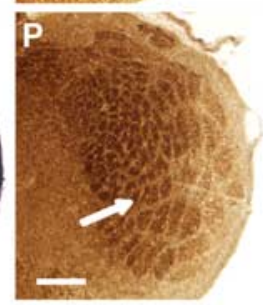

Avil-hPLAP mouse line is a useful tool to study diverse sensory endings in various organs and sensory axon projections in CNS

We have shown a few examples using AvilhPLAP to reveal exquisite sensory innervations in various organs (Figs. 3, 4), although clearly there are many other organs we have not yet explored, such as the sexual and the visceral organs. The almost exclusive expression of Avil-hPLAP in peripheral sensory neurons and their axons from embryonic stages into adulthood makes this line of mice an ideal tool for studying sensory neuron development, revealing specialized sensory endings in less studied organs, and for visualizing sensory projections under normal, injured, or pathological conditions. In addition, the Advillin locus can be used in the future to genetically manipulate mouse genomes in a sensory neuron-specific manner.

\section{References}

Archer SK, Claudianos C, Campbell HD (2005) Evolution of the gelsolin family of actinbinding proteins as novel transcriptional coactivators. BioEssays 27:388-396.

Chen CL, Broom DC, Liu Y, de Nooij JC, Li Z, Cen C, Samad OA, Jessell TM, Woolf CJ, Ma Q (2006) Runx1 determines nociceptive sensory neuron phenotype and is required for thermal and neuropathic pain. Neuron 49:365-377.

Coggeshall RE, Lekan HA, Doubell TP, Allchorne A, Woolf CJ (1997) Central changes in primary afferent fibers following peripheral nerve lesions. Neuroscience 77:1115-1122.

Datwani A, Iwasato T, Itohara S, Erzurumlu RS (2002) Lesion-induced thalamocortical axonal plasticity in the $\mathrm{S} 1$ cortex is independent of NMDA receptor function in excitatory cortical neurons. J Neurosci 22:9171-9175.

Davies A, Lumsden A (1984) Relation of target encounter and neuronal death to nerve growth factor responsiveness in the developing mouse trigeminal ganglion. J Comp Neurol 223:124-137.

Eng SR, Lanier J, Fedtsova N, Turner EE (2004) Coordinated regulation of gene expression by Brn3a in developing sensory ganglia. Development 131:3859-3870.

Erzurumlu RS, Killackey HP (1983) Development of order in the rat trigeminal system. J Comp Neurol 213:365-380.

Erzurumlu RS, Chen ZF, Jacquin MF (2006) Molecular determinants of the face map development in the trigeminal brainstem. Anat Rec A Discov Mol Cell Evol Biol 288:121-134.

Fundin BT, Arvidsson J, Aldskogius H, Johansson O, Rice SN, Rice FL (1997a) Comprehensive immunofluorescence and lectin binding analysis of intervibrissal fur innervation in the mystacial pad of the rat. J Comp Neurol 385:185-206.

Fundin BT, Silos-Santiago I, Ernfors P, Fagan AM, Aldskogius H, DeChiara TM, Phillips HS, Barbacid M, Yancopoulos GD, Rice FL (1997b) Differential dependency of cutaneous mechanoreceptors on neurotrophins, trk receptors, and P75 LNGFR. Dev Biol 190:94-116.

Harel NY, Strittmatter SM (2006) Can regenerating axons recapitulate developmental guidance during recovery from spinal cord injury? Nat Rev Neurosci 7:603-616.

Hodge LK, Klassen MP, Han BX, Yiu G, Hurrell J, Howell A, Rousseau G, 
Lemaigre F, Tessier-Lavigne M, Wang F (2007) Retrograde BMP signaling regulates trigeminal sensory neuron identities and the formation of precise face maps. Neuron 55:572-586.

Lazarov NE (2002) Comparative analysis of the chemical neuroanatomy of the mammalian trigeminal ganglion and mesencephalic trigeminal nucleus. Prog Neurobiol 66:19-59.

Leighton PA, Mitchell KJ, Goodrich LV, Lu X, Pinson K, Scherz P, Skarnes WC, Tessier-Lavigne M (2001) Defining brain wiring patterns and mechanisms through gene trapping in mice. Nature 410:174-179.

Li Y, Erzurumlu RS, Chen C, Jhaveri S, Tonegawa S (1994) Whisker-related neuronal patterns fail to develop in the trigeminal brainstem nuclei of NMDAR1 knockout mice. Cell 76:427-437.

Marks PW, Arai M, Bandura JL, Kwiatkowski DJ (1998) Advillin (p92): a new member of the gelsolin/villin family of actin regulatory proteins. J Cell Sci 111:2129-2136.

McKemy DD, Neuhausser WM, Julius D (2002) Identification of a cold receptor reveals a general role for TRP channels in thermosensation. Nature 416:52-58.

Mirnics K, Koerber HR (1995) Prenatal development of rat primary afferent fibers: II. Central projections. J Comp Neurol 355:601-614.

Mosconi TM, Rice FL (1993) Sequential differentiation of sensory innervation in the mystacial pad of the ferret. J Comp Neurol 333:309-325.

Mullen RJ, Buck CR, Smith AM (1992) NeuN, a neuronal specific nuclear protein in vertebrates. Development 116:201-211.

Navarro X, Verdu E, Wendelschafer-Crabb G, Kennedy WR (1997) Immunohistochemical study of skin reinnervation by regenerative axons. J Comp Neurol 380:164-174.

Payne J, Middleton J, Fitzgerald M (1991) The pattern and timing of cutaneous hair follicle innervation in the rat pup and human fetus. Brain Res Dev Brain Res 61:173-182.

Peier AM, Moqrich A, Hergarden AC, Reeve AJ, Andersson DA, Story GM, Earley TJ, Dragoni I, McIntyre P, Bevan S, Patapoutian A (2002) A TRP channel that senses cold stimuli and menthol. Cell 108:705-715.

Pinson KI, Dunbar L, Samuelson L, Gumucio DL (1998) Targeted disruption of the mouse villin gene does not impair the morphogenesis of microvilli. Dev Dyn 211:109-121.

Rausa F, Samadani U, Ye H, Lim L, Fletcher CF, Jenkins NA, Copeland NG, Costa RH (1997) The cut-homeodomain transcriptional activator HNF-6 is coexpressed with its target gene HNF-3 beta in the developing murine liver and pancreas. Dev Biol 192:228-246.

Ravenall SJ, Gavazzi I, Wood JN, Akopian AN (2002) A peripheral nervous system actin-binding protein regulates neurite outgrowth. Eur J Neurosci 15:281-290.

Rebsam A, Seif I, Gaspar P (2005) Dissociating barrel development and lesion-induced plasticity in the mouse somatosensory cortex. J Neurosci 25:706-710.

Rice FL, Fundin BT, Arvidsson J, Aldskogius H, Johansson O (1997) Comprehensive immunofluorescence and lectin binding analysis of vibrissal follicle sinus complex innervation in the mystacial pad of the rat. J Comp Neurol 385:149-184.

Rossi F, Gianola S, Corvetti L (2007) Regulation of intrinsic neuronal properties for axon growth and regeneration. Prog Neurobiol 81:1-28.

Rowe M, Iwamura Y (2001) Somatosensory processing: from single neuron to brain imaging. Newark, NJ: Harwood Academic.

Scarisbrick IA, Jones EG (1993) NCAM immunoreactivity during major developmental events in the rat maxillary nerve-whisker system. Brain Res Dev Brain Res 71:121-135.
Schlaggar BL, Fox K, O’Leary DD (1993) Postsynaptic control of plasticity in developing somatosensory cortex. Nature 364:623-626.

Schlosser G (2006) Induction and specification of cranial placodes. Dev Biol 294:303-351.

Schofield JN, Day IN, Thompson RJ, Edwards YH (1995) PGP9.5, a ubiquitin C-terminal hydrolase: pattern of mRNA and protein expression during neural development in the mouse. Brain Res Dev Brain Res $85: 229-238$.

Schwab J, He Z (2007) Mechanisms of axon regeneration. In: Intracellular mechanisms for neuritogenesis (De Curtis I, ed), pp 302-325. New York: Springer.

Shah NM, Pisapia DJ, Maniatis S, Mendelsohn MM, Nemes A, Axel R (2004) Visualizing sexual dimorphism in the brain. Neuron 43:313-319.

Shibata M, Ishii J, Koizumi H, Shibata N, Dohmae N, Takio K, Adachi H, Tsujimoto M, Arai H (2004) Type F scavenger receptor SREC-I interacts with advillin, a member of the gelsolin/villin family, and induces neuritelike outgrowth. J Biol Chem 279:40084-40090.

Silacci P, Mazzolai L, Gauci C, Stergiopulos N, Yin HL, Hayoz D (2004) Gelsolin superfamily proteins: key regulators of cellular functions. Cell Mol Life Sci 61:2614-2623.

Story GM, Peier AM, Reeve AJ, Eid SR, Mosbacher J, Hricik TR, Earley TJ, Hergarden AC, Andersson DA, Hwang SW, McIntyre P, Jegla T, Bevan S, Patapoutian A (2003) ANKTM1, a TRP-like channel expressed in nociceptive neurons, is activated by cold temperatures. Cell 112:819-829.

Streit A (2004) Early development of the cranial sensory nervous system: from a common field to individual placodes. Dev Biol 276:1-15.

Tominaga M, Caterina MJ, Malmberg AB, Rosen TA, Gilbert H, Skinner K, Raumann BE, Basbaum AI, Julius D (1998) The cloned capsaicin receptor integrates multiple pain-producing stimuli. Neuron 21:531-543.

Van der Loos H, Woolsey TA (1973) Somatosensory cortex: structural alterations following early injury to sense organs. Science 179:395-398.

Van Exan RJ, Hardy MH (1980) A spatial relationship between innervation and the early differentiation of vibrissa follicles in the embryonic mouse. J Anat 131:643-656.

Wang KH, Brose K, Arnott D, Kidd T, Goodman CS, Henzel W, TessierLavigne M (1999) Biochemical purification of a mammalian slit protein as a positive regulator of sensory axon elongation and branching. Cell 96:771-784.

Wang XZ, Harding HP, Zhang Y, Jolicoeur EM, Kuroda M, Ron D (1998) Cloning of mammalian Ire1 reveals diversity in the ER stress responses. EMBO J 17:5708-5717.

Willis WJ, Coggeshall R (1988) Sensory mechanisms of the spinal cord. New York: Kluwer.

Woolf CJ, Shortland P, Coggeshall RE (1992) Peripheral nerve injury triggers central sprouting of myelinated afferents. Nature 355:75-78.

Woolf CJ, Shortland P, Reynolds M, Ridings J, Doubell T, Coggeshall RE (1995) Reorganization of central terminals of myelinated primary afferents in the rat dorsal horn following peripheral axotomy. J Comp Neurol 360:121-134.

Yamakado M (1999) Reassemblage of primary cell aggregates and modulation of subcortical connections in the thalamic relay nucleus: effects of vibrissal damage in the developing whisker-to-barrel pathway in the mouse. J Comp Neurol 403:517-533.

Zylka MJ, Rice FL, Anderson DJ (2005) Topographically distinct epidermal nociceptive circuits revealed by axonal tracers targeted to Mrgprd. Neuron 45:17-25. 